\title{
Erratum to: Trust-Based Routing Mechanism in MANET: Design and Implementation
}

\author{
Tameem Eissa • Shukor Abdul Razak • \\ Rashid Hafeez Khokhar • Normalia Samian
}

Published online: 16 November 2013

(C) Springer Science+Business Media New York 2013

Erratum to: Mobile Netw Appl (2013) 18:666-677

DOI 10.1007/s11036-011-0328-0

The original version of this article unfortunately contained a mistake in Author's affiliation. The correct affiliations are presented below.

The online version of the original article can be found at http://dx.doi.org/ 10.1007/s11036-011-0328-0.

T. Eissa $\cdot$ S. Abdul Razak $(\bowtie) \cdot$ R. H. Khokhar

Universiti Teknologi Malaysia, Johor Bahru, Malaysia

e-mail: sabdrazak@gmail.com

N. Samian

Universiti Putra Malaysia, Selangor, Malaysia 